\title{
MEMORIA, TRANSGRESIÓN Y RETÓRICA EN EL LABERINTO DE FORTUNA DE JOSÉ MANUEL CABALLERO BONALD
}

JULIO NEIRA

UNED

jneira@flog.uned.es

\section{RESUMEN}

La obra de José Manuel Caballero Bonald presenta como ejes principales de su poética la función de la memoria personal como generadora de la creación, su carácter reactivo y disidente respecto a las circunstancias sociales y políticas de su tiempo y la transmutación de las experiencias vitales y colectivas en una experiencia esencialmente literaria mediante un proceso de elaboración artística del lenguaje. En este estudio se analiza la presencia de esas tres claves en Laberinto de Fortuna, uno de los libros más representativos de su trayectoria: la huella de su biografía, los textos críticos con el proceso de la transición política española y el empleo de procedimientos de la retórica clásica en la construcción de un poemario eminentemente transgresor.

Palabras clave: José Manuel Caballero Bonald, Laberinto de Fortuna, biografía, memoria personal, retórica clásica, transgresión poética.

\section{Abstract}

The main axes of José Manuel Caballero Bonald's poetry are: personal memory as the origin of literary creation, dissent from social and political circumstances, and the transformation of individual and collective life events into literary experience through the poetic elaboration of language. This essay analyses these three keys - the deploy- 
ment of biographical traces, the critical consideration of the Spanish political «transición» and the use of Classical rhetoric_-in one of the most representative and poetically transgressive poetry collections of his career, Laberinto de Fortuna.

Key words: José Manuel Caballero Bonald, Laberinto de Fortuna, biographical traces, personal memory, Classical rhetoric, transgressive poetry.

Los estudiosos y críticos de la obra de José Manuel Caballero Bonald ${ }^{1}$, y él mismo en las numerosas entrevistas de prensa que ha concedido, ${ }^{2}$ suelen coincidir en señalar como claves de su obra poética tres aspectos fundamentales: el papel de la memoria personal como desencadenante de la creación, su carácter vindicativo ante las afrentas de toda índole con que la realidad socava la dignidad del ser humano, y la reelaboración de la experiencia vital en el ámbito del lenguaje para transmutarla en una experiencia esencialmente literaria. Tres dimensiones: una biográfica, otra social y otra artística que conforman una poética personalísima, vinculada a las preocupaciones estéticas de su tiempo pero inmune al gregarismo de las modas. Después de comprobar su original simbiosis en dos de sus libros más destacados: Descrédito del héroe y Manual de infractores ${ }^{3}$ veamos ahora cómo actúan en Laberinto de Fortuna (1984).

En Laberinto de Fortuna encontramos bastantes ejemplos de esa voluntad de aplicar la memoria como fuente de la escritura y recuperar momentos del pasado más o menos remoto, dejándose llevar por la «Seducción de ese remoto espacio de nuestra juventud que decanta, retiene todo el tiempo del mundo. Y toda la pasión de seguir cotejando impunemente constancias con olvidos» $(379)^{4}$. En ese cotejo afloran las experiencias infantiles en el desván de la casa familiar en aquellos jueves sin colegio en «Por nada del mundo» y en «De la creencia infantil en la lluvia»; la enfermedad pulmonar de la juventud en «Espacio cerrado»; la visita a un burdel de Xauen en el lejano verano de 1950 en «Cuarto creciente»; la contemplación de la desembocadura del Ródano tan simétrica a la del Guadalquivir y la ciénaga de Doñana durante un viaje a Francia en «Bouches-du-Rhône»; la escena de vagabundos en una plaza de Estocolmo durante su asistencia al Congreso del PEN Club Internacional en 1978 en «Medborgarplatsen»; el viaje a Perú de 1979 en «Lima de piedra»; el de Rumanía en 1970 en «Incompetencia del pasado»; y, en fin, la siempre trágica experiencia de la muerte de la madre en el poema «Después».

Pero no es necesario encontrar una anécdota, un viaje o un episodio concretos, muchos de sus poemas se refieren a recuerdos íntimos o eróticos, actitudes personales, formas de ser o modos de actuar en la vida, no siempre edificantes, sobre los que el autor

\footnotetext{
${ }^{1}$ Véase sobre todo el estudio Payeras, María (1997): Memorias y suplantaciones. La obra poética de Caballero Bonald, Palma de Mallorca, Universitat Illes Balears.

2 Algunas han sido recopiladas por Pedrós-Gascón, Antonio F. (2011): en José Manuel Caballero Bonald. Regresos a Argónida en 33 entrevistas, Prensas Universitarias de Zaragoza.

${ }^{3}$ Véase Neira, Julio, «José Manuel Caballero Bonald, una poética de la transgresión», en Caballero Bonald, José Manuel (en prensa), Descrédito del héroe y Manual de infractores, Madrid, Cátedra.

${ }^{4}$ En todos los casos cito los textos por la edición Caballero Bonald, José Manuel (2011), Somos el tiempo que nos queda, Barcelona, Seix Barral, Colección Austral. El número entre paréntesis tras cada cita corresponde a la página.
} 
realiza un auténtico examen de conciencia, como en «Contra Séneca»: «El pasado conserva todavía un acusado tono virulento, a trechos macerado en una huraña mezcla de semen y alcohol». Con razón afirmó Aurora de Albornoz que distaba de ser arbitraria la elección del título de la primera recopilación de su poesía: Vivir para contarlo. ${ }^{5}$ El ejercicio mismo de la memoria y sus adulteraciones, simulacros y coartadas, o la imperceptible frontera entre sueño y recuerdo, realidad y ficción, es materia poética de varios textos, como «Epístola censoria» («Evoco al que no he sido todavía»), «Luz genital» («Recuerda mientras tanto la historia que no has vivido todavía»), «Paréntesis» («Esa fortuita agresión del recuerdo que arrasa filialmente tu sigilosa historia personal»), «Demasiadas preguntas» («Sólo se reconoce quien se olvidó de pronto de sí mismo»), «Tengo mis dudas» («Algo que se me olvida rivaliza por fin con lo más recordable»), «Crecimiento cero» («los sueños que la imaginación hace verídicos»), «Pluscuamperfecto» (No sé si fue ayer tarde o fue pasado mañana»), «Teatro privado» («Sólo el presente puede modificar el curso del pasado»), etc., porque, como recientemente ha advertido María José Flores, junto a la memoria de las experiencias vividas encontramos en sus poemas:

la rememoración de lo inventado, de lo que podría haber sido, de lo verosímil poético; la memoria de lo que él mismo denomina «memoria fingida» [...] continuo «juego» que no permite distinguir lo real de lo ficticio, que los confunde, y que hace que todo pueda ser considerado, al mismo tiempo, como realmente autobiográfico, y como realmente ficticio. ${ }^{6}$

Tal vez por ello Caballero Bonald confiesa en La costumbre de vivir haber procurado «que la experiencia actuara como un resorte lingüístico del personaje del poema, el mismo que iba inventándose su propia verdad a medida que avanzaban los artificios consecutivos del texto» ${ }^{7}$. En suma, el arte es más importante que la vida y lo verídico se somete a lo verosímil en orden al resultado literario. Quizás en Laberinto de Fortuna hallemos la formulación más explícita al respecto: «Nunca la realidad pudo ser sustentada sin aportar su parte de ficción» («Comedor de loto»), «No sin ser deformada puede la realidad exhibir sus enigmas» («Femme nиe») y «Mi oficio es esta forma de imponerle al recuerdo una distinta ambigüedad, ese soberbio modo de hacer más seductora una experiencia que habrá quien considere deleznable: cuanto aquí dejo escrito legitima eso otro que nunca escribiré» («Capvespre a Lluch-Alcari»).

Por lo que se refiere al segundo elemento definidor de su poesía, su carácter reactivo a las injusticias del orden social y la vida política, conviene recordar que tras su estancia en la cárcel de Carabanchel en $1966^{8}$ declaró a Jean Michael Fossey su convicción de que la literatura estaba íntimamente ligada a la ideología, que es parte fundamental de la vocación literaria, aunque nunca debía subordinarse a ella, y un año después reafirmaba esta formulación en el cuestionario para la Antología de la nueva poesía española elaborada por José Batlló:

5 Albornoz, Aurora de (1970): «La vida contada, de J. M. Caballero Bonald», Revista de Occidente, 87, pág. 328.

${ }^{6}$ Flores, María José (2013): «Soy esos hombres juntos: identidad y ficción en la obra poética de JMCB», Cuadernos AISPI. Estudios de lenguas y literaturas hispánicas, Milán, 1/2013, págs. 172-173.

7 Caballero Bonald, José Manuel (2001): La costumbre de vivir, Madrid, Alfaguara, pág. 579.

${ }^{8}$ Sobre este y otros episodios de su biografía, véase NeIRA, Julio (2014): Memorial de disidencias. Vida y obra de José Manuel Caballero Bonald, Sevilla, Fundación José Manuel Lara. 
Toda literatura nace del planteamiento de un conflicto entre el escritor y la realidad. Mi poesía y mi novela también han pretendido ser, a este respecto, la formulación de una personal experiencia conflictiva. Y no puedo escribir si no me siento en la inminente necesidad de defenderme de algo con lo que estoy en radical desacuerdo. El acto de escribir supone para mí un trabajo de aproximación crítica al conocimiento de la realidad y también de una forma de resistencia frente al medio que me condiciona9.

Desde los inicios, la poesía ha sido el mejor medio de expresión de su connatural disidencia con el mundo. Los vínculos entre Pliegos de cordel (1963) y la estrategia política antifranquista son muy evidentes. Frente a la propaganda del régimen, que se encaminaba al cuarto de siglo de paz impuesta, la estrategia de la oposición antifranquista consideró imprescindible mantener viva la memoria de lo ocurrido en la posguerra: la represión en todas sus formas, el adoctrinamiento dogmático, etc. El denominado realismo crítico se ocupó de aportar numerosos testimonios autobiográficos. Esa es la intención de este poemario escrito en su mayor parte en Colombia, donde la distancia incluso geográfica a los hechos permiten la recuperación de los recuerdos.

Mas ni siquiera la muerte del dictador y la recuperación de la libertad produjo en Caballero Bonald el apaciguamiento de su espíritu. De hecho, su intención crítica seguirá siendo esencial en poemarios posteriores, desde Descrédito del héroe a Manual de infractores, que surge, casi a destiempo, cuando parecía haber concluido la labor como poeta, por impulso de su radical disidencia con la situación de la política española a principios del siglo XXI; y llega a su plenitud en Entreguerras, donde el espíritu insumiso del poeta se manifiesta poderoso en el recuento autobiográfico.

Laberinto de Fortuna reunió en 1984 textos escritos desde la publicación de Descrédito del héroe en 1977, cuyo significado transgresor y voluntad estética prolonga en gran medida. Son los años de la transición política desde un régimen dictatorial a un sistema democrático, del fin del franquismo al triunfo del PSOE y el primer gobierno de izquierdas después de la República. Un periodo que tantas y tan convulsas experiencias hizo sufrir a la sociedad española: atentados, asesinatos y secuestros terroristas de la ultraizquierda, del irredentismo vasco y de la extrema derecha, la intoxicación colectiva producida por el aceite de colza adulterado, varios intentos de golpe de estado militar, el del 23-F el más conocido, la consolidación titubeante de la monarquía, el auge y brusco ocaso del partido de la UCD, etc.

Todos esos acontecimientos históricos fueron vividos con verdadera ansiedad y mucha incertidumbre por el conjunto de la sociedad, y por José Manuel Caballero Bonald, protagonista de primera fila en los estertores del franquismo como miembro de la Junta Democrática, plataforma de organizaciones e intelectuales vinculados al Partido Comunista creada para forzar una salida democrática a la dictadura y recuperar la libertad en España. Las cosas no fueron como la Junta Democrática deseaba, pues su fusión con el bloque de fuerzas socialistas en Coordinación Democrática, conocida como la Platajunta, derivó en un pacto con los grupos liberales del franquismo para lograr una Transición reformista y no una ruptura radical con la dictadura. Ello hizo posible la «reinvención» democrática de protagonistas de la dictadura —el ex ministro de Franco Manuel Fraga

${ }^{9}$ Batlló, José (1968): Antología de la nueva poesía española, Madrid, Ciencia Nueva, pág. 332. 
Iribarne el más destacado-, y la impunidad de los atropellos y crímenes cometidos durante las décadas anteriores. La Ley de Amnistía supuso en octubre de 1977 un borrón y cuenta nueva que indignó al poeta primero y le descorazonó después, hasta convencerle de que el franquismo no llegaría a ser erradicado nunca de la sociedad española, ni habría una vindicación histórica de sus víctimas.

En la línea de poemas de Descrédito del héroe como «Presente histórico», «Supremum vale», «Servicio prestado», «Glorias heredadas», «Inutilidad de los antídotos», «No molesten, por favor», «Rigor mortis», etc., en Laberinto de Fortuna Caballero Bonald da una respuesta poética contundente a las vicisitudes de la realidad política española en ese periodo y a los fundamentos de la moral social, observadas desde una perspectiva muy crítica. El espacio disponible ahora no permite profundizar en el sentido de sus alegatos contra toda manifestación de monolitismo ideológico, de intransigencia, de imposición sobre las conciencias, de coacciones a la libertad del ser humano en aras al mantenimiento de una sociedad organizada sobre el beneficio del capital a costa del sufrimiento de los más débiles, o contra la hipocresía con que se comportan los poderosos, sus acólitos y las jerarquías eclesiásticas para mantener un poder terrenal fundado en la promesa de una liberación ulterior. Hemos de limitarnos a relacionar los poemas más significativos en esta clave temática.

Con singular énfasis denuncia la esencia del Nacionalcatolicismo, el régimen que había sustentado una España sometida a la complicidad de militares y eclesiásticos, y su intento de pervivencia en la transición en «Conquistas»: «¿Los que heredaron cruces y venablos son los mismos que heredan todavía armas de fuego y pilas bautismales?») y en «Santo Oficio»: «Alrededor de las persecuciones hay siempre un subrepticio vendedor de jaculatorias»; así como el relato justificador del totalitarismo en «Mientras tanto todavía»:

También esa historia fue amañada por sus protagonistas [...] atribuyó el triunfante a su exterminio sino abyectos deberes de conciencia, cobardes militancias apostólicas, fueros de un latrocinio que la misma cultura consagrara: ese instinto culpable que yo también un día recibí como herencia de los míos.

Caballero Bonald fustiga con acritud y sarcasmo la mediocridad de los protagonistas de la administración en «Me hago cargo»; la atrabiliaria conducta de los prohombre del franquismo en «Epitafio para musarañas»: «dedicó sus últimos fervores a quemar a insurrectos en efigie», y en «Molusco de jardín»: «Ingería una enorme cantidad de impudor mientras hablaba y una baba epicúrea le pendía del labio como un resentimiento»; la incapacidad de los discursantes en «Orador puntiagudo»: «vocifera el gárrulo de turno [...] ufano finalmente de poder injertar la vanagloria en la grandilocuencia»; o la degradación de la vida pública y el servilismo en «Bloque genético»: «esa gloria no efímera que encumbra por igual a petimetres, atletas, locutores, caciques [...] una herencia de fámulos asegura también el galardón adicional de la obediencia ciega». En todos los casos la clave paródica le aproxima a la tradición satírica de clara estirpe barroca.

Proclama la necesidad de una insurrección moral frente al dogmatismo estatuido y defiende el valor de la rebeldía: «sublevarse sin más contra los mandamientos de esa abyecta invasión de bienpensantes» («Opus equis»). En «Inseguridad ciudadana»se queja de los «farragosos ediles que deploran mis actos con una edulcorada impudicia de 
mártires»; en «Otros primores de lo vulgar» alerta contra «la timorata geometría de quien cerca su vida de obediencias»; y en «Examen de ingenios» se burla de las reuniones profesionales: «Un simposio de acólitos exonera sus cuitas intramuros del centro parroquial [...] la intrepidez no agota la estulticia». El rechazo de las verdades inmutables («ninguna verdad es la misma dos veces», «Ítem más»; «nunca es del todo fidedigno lo que no admite dudas», «Sumario cero»)) y el elogio de la independencia de criterio personal se convierten en principio de su convicciones: «no creer en nada parecido a esa virtud mugrienta que arrastra a los gregarios» («Ítem más»). Esa indesmayable actitud crítica ante los desafueros de la realidad social le convirtió en un referente inexcusable de intelectual progresista comprometido con su tiempo.

Desde un principio José Manuel Caballero Bonald fue consciente de que la esencia de la poesía es el lenguaje. En él y no en el contenido, ni en la anécdota que lo genera, se centra la verdadera naturaleza del fenómeno poético. Ya en sus libros iniciales supo ver la crítica una novedosa pretensión de riqueza verbal, de búsqueda de una dimensión nueva al lenguaje por todos compartido que le hiciera alumbrar una nueva realidad lingüística sólo existente en el poema, lo que hacía su voz distintiva en un tiempo dado a una expresión poética más directa, que pretendía servir de comunicación entre los seres humanos en un tiempo de angustiada desolación individual y social. ${ }^{10}$

No debió de ser ajena a esa indagación en las posibilidades del lenguaje su conocimiento profundo de los poetas barrocos españoles. En 1957 se imbuyó de lírica áurea al preparar por encargo de Carlos Barral una antología de la poesía del siglo XVII que no llegaría a publicarse. Luego, en 1982 editó la poesía de Góngora, ${ }^{11}$ y en 2005 la de Cervantes. ${ }^{12}$ Más tarde, ya en la década de los sesenta, el descubrimiento de la literatura hispanoamericana, en especial de la del cubano José Lezama Lima, le convirtió en un decidido defensor de la experimentación del lenguaje como núcleo del oficio de poeta. En la entrevista de Luis García Montero citada afirmará:

El lenguaje es para mí una ética, una reflexión ético-estética. Mi ética, mi responsabilidad como escritor consiste en mi trabajo artístico con el lenguaje, en la búsqueda de un lenguaje que se corresponda con esa aproximación al conocimiento de la realidad. Las palabras que yo uso son las que mejor hablan de mí. Tiendo a que esas palabras signifiquen más de lo que significan con los diccionarios. Si no fuese así, a lo más que llegaría es a ser un copista. El estilo es la vida. ${ }^{13}$

Es cierto que durante unos años — los que correspondieron a la llamada «operación realista» de la Colección Colliure: 1959-1963 - esa voluntad de estilo fue subordinada al pragmatismo político con que la poesía se puso al servicio de la lucha antifranquista.

${ }^{10}$ Véanse por ejemplo las reseñas a Las adivinaciones de Carlos Edmundo de Ory, Poesía española, IV, abril 1952, Ángel Valbuena Briones en Índice, 15 junio 1952, y Gerardo Diego en Correo literario, 54,15 agosto 1952; o las que hicieron a Memorias de poco tiempo Emilio Alarcos Llorach en Pliego crítico, Universidad de Oviedo, mayo-diciembre 1955, José María Castellet en Correo literario, segunda época, 10, febrero-marzo 1955, y José Ángel Valente en Índice, junio 1955. Taurus.

11 Góngora, Luis de (1982): Poesía. Introducción y selección de José Manuel Caballero Bonald, Madrid,

${ }^{12}$ Cervantes, Miguel de (2005): Poesía, selección e introducción de José Manuel Caballero Bonald, Barcelona, Seix Barral.

13 García Montero, Luis (2007): «Preguntas/respuestas», Navegante solitario, Litoral, 242 pág. 26. 
Mas pronto se hizo evidente que con tiradas tan escasas y distribución tan precaria era imposible incitar a la clase trabajadora a un levantamiento contra la dictadura. Aunque algunos perduraron algunos años más en esa estética del llamado realismo crítico o social, José Manuel Caballero Bonald inició en 1964 un camino irreversible hacia la transmutación de la experiencia mediante el crisol del lenguaje poético, en busca de precisión — «hallar la palabra justa para contar lo vivido», en palabras de Aurora de Albornoz-, ${ }^{14}$ pero también de generar nuevas posibilidades expresivas, lo que Pere Gimferrer denominó su «capacidad autogenésica»; ${ }^{15}$ que culmina en Entreguerras con un extraordinario ejercicio de transgresión vivificadora del lenguaje establecido, demostrativo de que la belleza de la expresión es compatible con la dureza o sordidez de lo expresado, y que no es cierto que haya que depauperar la palabra poética para alcanzar un eficaz proceso de comunicación, lo que le vincula directamente con cimas de nuestra lírica como Quevedo o Góngora. La convicción de Caballero Bonald es que ética y estética no son opuestos que se rechacen, sino formantes indisolubles de la dignidad del creador artístico.

No fue capricho titular su libro Laberinto de Fortuna, según confesión del autor como homenaje a Juan de Mena, que cinco siglos antes en sus Trescientas había abierto «el foco dinástico de las grandes innovaciones retóricas de nuestra cultura literaria», contraviniendo la norma lingüística e instaurando «la frontera prerrenacentista de un nuevo linaje poético» ${ }^{16}$. Linaje en el que muy conscientemente él entronca este conjunto de textos que aprovecha los resortes de la retórica áurea para intensificar expresivamente su alegato transgresor, tanto en un sentido político y social como en el plano estético, y a esa voluntaria filiación responde la presencia intertextual de versos de Rodrigo Caro («Serias dificultades para mirar de lejos»), Cervantes («Bouches du Rhône»), Fray Luis de León («El aire se serena»), Lope de Vega («Sombras le avisaron») o Góngora («Vacación interrupta»).

La primera transgresión consiste en dotar a la poesía de aspecto de prosa, cuando no lo es. No se trata ni de poemas en prosa ni de prosa poética, sino de poemas cuyos versos se disponen continuados, sin su habitual distribución lineal. Es la misma silva libre impar que caracteriza sus otros poemarios, sólo que sin cesura versal. Esto creó no pocas disquisiciones sobre el género de los textos en las primeras reseñas, pero un análisis mínimamente riguroso detecta enseguida el procedimiento, con el que Caballero Bonald llama la atención sobre el hecho de que la naturaleza del fenómeno poético no estriba en la disposición gráfica, sino en su ritmo interno. Bastará como ejemplo el poema «Zephyrum», cuya composición a base de heptasílabos, eneasílabos, endecasílabos y un alejandrino señalamos a continuación:

Cero inflexible que regula $\left[9^{\circ}\right]$ el sobrante numérico de nada: $\left[11^{\circ}\right]$ pretexto fronterizo de la ausencia: $\left[11^{\circ}\right]$ su silencio remite a otra pauta $\left[11^{\circ}\right]$ más neutra de silencio: $\left[7^{\circ}\right]$ magnitud que comienza donde acaba: [11] esa contravención del infinito $\left[11^{\circ}\right]$ que oculta una contraria geometría: $\left[11^{\circ}\right]$ el vacío es simétrico: $\left[7^{\circ}\right]$ su nulidad se nutre de su propia carencia: $\left[7^{\circ}+7^{\circ}\right]$ cifra nonnata y número perpetuo: $\left[11^{\circ}\right]$ mi negación y mi palabra. $\left[9^{\circ}\right]$

14 Albornoz, Aurora de (1970), «La vida contada, de J. M. Caballero Bonald», pág. 328.

15 Gimferrer, Pere (1989), prólogo a la antología Doble vida, Madrid, Alianza, pág. 10.

${ }^{16}$ Caballero Bonald, José Manuel (2011): Somos el tiempo que nos queda, pág. 359-360. La obra de Juan de Mena había gozado en 1976 de una edición a cargo de Miguel Ángel Pérez Priego (Madrid, Editora Nacional) que actualizó el interés por la obra del poeta cordobés. 
Los dos últimos versos son también un excelente ejemplo de cómo Caballero Bonald emplea los mejores recursos estilísticos de la retórica clásica al servicio de una poesía de tan rompedor contenido, aquí la bimembración paralelística, que refuerza la esticomitia del verso con la simetría sintáctica, que tan buenos resultados ha dado desde la lírica renacentista. Ya Salvador Hernández Alonso apuntó en su reseña del libro ${ }^{17}$ la presencia de algunas figuras retóricas, pero ni de lejos llegó a percibir hasta qué punto Laberinto de Fortuna fundamenta sus códigos estilísticos en ese riquísimo caudal que regula la transmutación de la lengua cotidiana en lenguaje poético.

Ejemplos de estructuras bimembres son frecuentes en bastantes poemas, y varias se presentan duplicadas como los que acabamos de ver, tanto con sustantivos: «de sudor y cosmético, de alcuza y delantal» (370), como adjetivales: «Jactanciosos y adustos, incautos y epicenos» (386), «juntos y pretéritos, amorfos y silentes» (407), «tentacular y frondio, voraz y discontinuo» (412). El paralelismo de estructuras sintácticas, sean nominales: «tu mezquina desnudez, tu altiva dependencia» (372), «de emoción el paisaje, de rigor lo ilusorio» (392), «Banderas como garras, báculos como garfios» (391); o verbales: «Vociferan las líneas, gesticulan las formas» (425), es otra manera de dotar de poeticidad al lenguaje. No necesariamente la simetría es perfecta, pero la bimembración se percibe con claridad, y en ocasiones se triplica en el mismo poema, como en «Cuarto creciente»o «Lima de piedra»: «Impregnaba su rostro una tintura glandular y dinástica, como de coca y frailejón, de saliva de enferma y maíz fermentado» (414), de manera que un recurso se integra en otro, la trimembración.

La sucesión de tres elementos es la más abundante pauta sintagmática del lenguaje de este poemario, tanto que su recuento minucioso desbordaría el límite razonable a estas páginas. Veamos sólo algunos ejemplos significativos. Las estructuras trimembres - igualmente profusas en la lírica barroca — son decisivas para la magnificencia verbal del personal estilo de Caballero Bonald. Pueden estar formadas por la yuxtaposición de sustantivos, como «apaciguaba los papeles, las pugnas, los cansancios» (365), «en tertulias, parroquias, consistorios» (390), «fracasos, incurias, malandanzas» (416); de adjetivos: «el amorfo, el tenaz y oxidado material del deseo» (376), «Hay días espasmódicos, abruptos, sucios por dentro» (408), «el heroico, el invicto, el sobrehumano poder del errabundo» (410); o de sintagmas nominales, como « espesura de espinas, orín de arengatorio, repelente viruta occipital» (409), «llegó a las puertas condenadas de Nínive, al muro funeral de Babilonia, al usurpado trono de Tartessos» (410). El número tres también estructura sintagmas verbales como «La lujuria del luto contamina el negro corazón de los cipreses, repta por la musgosa claridad que profana los mármoles, invade el pedregal...» (413), «Gimen los artesones, crepita la humedad detrás de los espejos, se cuartean las manos y los mármoles» (427). Y en algunas ocasiones llegamos a hallar ejemplos de cuatro elementos en la yuxtaposición: «El buscador de la certeza se equivoca de claves, predicciones, dogmas, abecedarios» (373), «que encumbra por igual a petimetres, atletas, locutores, caciques» (418).

La trimembración puede estar apoyada por otra figura clásica de la sintaxis poética, como la anáfora: «Entre papeles, entre cuerpos, entre lecciones vociferantes» (420), «Ven-

${ }^{17}$ Hernández Alonso, Salvador (1985), «El Mundo de los Libros», Ínsula, 469, pág. 18. 
go de muchos libros... Vengo también de un viaje... vengo igual que de una madre» (451). Pero la anáfora aparece también sin esa apoyatura: «Guárdate de la noche... Guárdate de esa triste guarida... [...] ¿Eres... ¿O eres... [...] Nada más... nada tampoco» (372). También idiosincrática del lenguaje poético barroco es la aliteración, que proporciona sonoridad al texto poético, y sería inusual en uno de prosa. Ejemplos del dominio de esta figura retórica por nuestro poeta son el inicio de «La botella vacía»: «Solícito el silencio se desliza por la mesa nocturna, rebasa el irrisorio contenido del vaso» (376); el que él mismo define como «sonido agrio» con el alejandrino «hecho de disonantes rimeros del desuso» (365); o la majestuosa sonoridad de «Topa con los tapices la repugnante trompa wagneriana» (374) en el decadente ambiente de «Camafeo, daguerrotipo, partitura».

Según acabamos de ver, tanto en estructuras bimembres como trimembres es frecuente la acumulación de adjetivos, que al igual que en Descrédito del héroe son la base estilística que da a estos textos su peculiaridad más acusada. Una adjetivación que, como allí, se sustenta además en la reiteración del esquema gramatical — determinante + adjetivo + sustantivo + de + sintagma nominal- , que puede presentar algunas variantes, como la presencia de más de un adjetivo, su posposición respecto al sustantivo, o la presencia de adjetivos en el complemento determinativo, que puede tener también función adjetival. Nos referimos al tipo «las mucosidades difusas de la noche» (366), «Cíclica herida de entreabiertos párpados» (387) o «el estertor sincronizado de los necrófilos amantes» (413). La profusión de este patrón sintagmático en una gran parte de los poemas lo convierte en una especie de marca ideolectal del lenguaje poético del jerezano, y nos obliga a citar sólo algunos ejemplos muy relevantes, aquellos textos en los que utiliza su reiteración y otros usos del adjetivo para dotarlos de una ambientación especialmente sensorial. Así «Terra incógnita», que se refiere a su Argónida y al argumento de Ágata ojo de gato:

una incierta desmesura de pájaros...geométrico estruendo... el mismo aparente rumbo del barco... infrahumano estupor del extranjero... metódica equivocación en las ralas declinaciones de la bajamar...¿Presentían en aquel cerco traslaticio de arenas las tumbas subacuáticas del delta primitivo o acaso confundían la amarilla flor del jaguarzo con las profanaciones del oro argonidense?... efímeros los datos... hermética conjura... la visionaria profesión del náufrago (368).

En «Camafeo, daguerrotipo, partitura» el ambiente descrito es un decadente salón decimonónico:

Un ángel carininfo, de ademanes policromados, languidece detrás del canapé...el impávido tremolar de las alas...la indolente añagaza del piano de cola, el erecto sopor de los atriles... la misma imperturbable actividad de la carcoma... los tafetanes melindrosos... taciturno corazón de trapo...la repugnante trompa wagneriana... el deformante espejo del pasado... los baldaquinos de los buenos modales (374).

Y en Super flumina Babylonis —que toma su título del inicio del Salmo 136- hallamos al misterioso personaje femenino que aparece en buena parte de la obra de Caballero Bonald, revestido con una iconografía sensual y orientalizante, propia de lecturas de la adolescencia.

Aquella impávida, bellísima harapienta... la última portadora aborigen del talismán...la irreductible magnificencia de la vida...los zumos tórridos de las frutas y un dulce amago de 
miseria envolvía los ambulantes puestos de la plaza... incólume la densidad de los desperdicios... Junto a la edénica antigüedad del gran río... la más joven desterrada del mundo... las acongojantes marcas de la manumisa... el surco predatorio de quien naciera extramuros de la justicia (389).

En estas citas puede apreciarse el carácter de epíteto en algunos ejemplos, pero es mucho más frecuente que el sintagma nominal ofrezca una notable disonancia sémica entre el sustantivo y el adjetivo, pues este predica cualidades que no corresponden a aquel. En «geométrico estruendo» (368) la cualidad es lineal y corresponde al sentido de la vista, mientras el sustantivo pertenece al del oído, lo que origina una sinestesia que produce extrañeza en la lectura y obliga al lector a reinterpretar la imagen; y en «la rítmica hegemonía de los pezones» (375), la cualidad temporal de «rítmica» difícilmente puede predicarse de «hegemonía», aunque su unión produce una imagen múltiple muy sugerente. Esta ruptura de la concordancia sémica es muy frecuente. Adjetivos que en nuestra lengua tienen el sema - + ser animado — califican sustantivos que carecen de él y producen sintagmas como «al imán vejatorio de los vidrios» (371), «una voluptuosa actividad de levadura» (379) o «una enfurecida desavenencia de diagnósticos» (448); sustantivos abstractos son dotados de cualidades que corresponden al ámbito humano, como «espacio furibundo del insomnio» (394) o «vengativa contradicción de la semántica» (448); y cualidades de sustantivos concretos se aplican a abstractos: «la combustible cerrazón del útero». En bastantes ocasiones la calificación es contraria a la naturaleza del sustantivo, generalmente en el orden abstracto o moral, pero también en el físico o sensorial, lo que produce verdaderas antonimias, como en «furtiva espiral de lo inmóvil» (367), «delicado animal de majestuosa inclemencia» (372), «los sórdidos compromisarios de la sabiduría» (373), «sacrales lujurias» (375), «las intermitencias delictivas de la virtud» (384), «esa abyecta invasión de bienpensantes» (408), «una ingente escasez de pudor» (412) o «las esplendorosas covachas de Sanlúcar» (443).

El empleo de esta adjetivación extrañadora, que quiebra las reglas semánticas del lenguaje, hunde sus raíces en los movimientos vanguardistas de inicios del siglo XX y es una manera más de infracción, la de la forma al servicio del significado de todo el poemario. Pero la transgresión del sistema de valores se apoya también en el empleo de otra figura retórica, esta de pensamiento: la paradoja, igualmente abundante en muchos textos. Oraciones de sentido antitético o al menos contradictorio, que rayan a veces en el oxímoron, contribuyen de manera decisiva a mantener la insumisión a los dogmas del pensamiento burgués, el cuestionamiento de las verdades establecidas, la denuncia de las certezas de toda índole y la apología de la duda que son la más genuina actitud ante la vida de José Manuel Caballero Bonald, quien afirma en «Fundadas sospechas»: «El buscador de la certeza se equivoca de claves, predicciones, dogmas, abecedarios» (373). Título como este o como «Contribución a la perplejidad», «Demasiadas preguntas», «Tengo mis dudas», «Inseguridad ciudadana» o «Bona fide o los valores relativos» abundan en esa radical posición intelectual: «nunca es del todo fidedigno lo que no admite dudas» (404).

El cuestionamiento de la realidad alcanza a su propia naturaleza: « ¿No es lo visible ya lo menos verosímil? (397); «esa quimera comúnmente llamada realidad» (430), «la realidad absorbe de ordinario ese otro excedente de los sueños que la imaginación hace verídicos» (433). La incredulidad atañe a las dimensiones espacio temporales, el pasado, 
el futuro, lo vivido y lo imaginado, la memoria y la ficción: «Recuerda mientras tanto la historia que no has vivido todavía» (366), «Mi error ha consistido... en no haberme sabido equivocar cuando con más certeza pude hacerlo... salgo al mismo incorregible futuro del que vengo» (377), «También quien retrocede encontrará el futuro» (397), «Vengo también de un viaje absolutamente maravilloso que no hice nunca a Samarcanda» (451). Ni siquiera el ámbito de la cultura, la ciencia y el arte queda fuera de ese general descreimiento: «obcecadas variantes de la perfección... equilibrio irracional del arte... esa piadosa errata de la ciencia» (408), «La transgresión de la lógica conduce al predominio de la maravilla... la cartesiana proporción de la anarquía» (425). La denuncia de los valores morales que sostienen la sociedad burguesa es otro de los campos en que abundan las antítesis, basten dos ejemplos: «Elegir la certeza, ¿de qué impostura me hace tributario?... allí hiede de pronto la bondad, se pudre la pureza... El mugriento espesor del virtuoso colinda en todo caso con la sumaria pulcritud del réprobo» (420), o «esa estoica lección de la moral también denominada puta vida» (452), sentencia en un texto denominado significativamente «Contra Séneca».

Otras figuras retóricas contribuyen a generar la desconcertante incertidumbre a que el texto induce al lector, como la litote o atenuación, que afirma mediante la negación: «Ofrendas no traían, ni banderas tampoco, ni ninguna palmaria prevención» (386), «No de otra forma vocifera el gárrulo de turno» (409), «no es posible que nadie tenga fe en lo que es cierto (427); zeugmas, anástrofes, epanadiplosis, hipérbatos, etc., cuya cita haría interminables estas líneas. Y deben hacerlo, concluyendo que en Laberinto de Fortuna, uno de sus libros menos atendidos por la crítica, José Manuel Caballero Bonald demuestra un profundo conocimiento de la tradición poética y el dominio de sus procedimientos retóricos para construir un duro alegato transgresor contra el andamiaje de principios y valores en que se asienta la sociedad contemporánea, intensificando la apuesta de Descrédito del héroe y anticipando la diatriba de Manual de infractores. 
